\title{
Una experiencia en la conservación de artefactos arqueológicos: práctica de campo en el Museo de Sitio de Alta Vista, Zacatecas, noviembre del 2009
}

\author{
Adriana Sanromán Peyron \\ Jessica Avecilla Zapata \\ Mariana Flores Hernández
}

Introducción

\begin{abstract}
- I presente artículo versa sobre las actividades Ilevadas a cabo por el Se-
- minario-Taller Optativo de Rescate Arqueológico (STORARQ) de la Escuela - Nacional de Conservación, Restauración y Museografia (ENCRyM) del Instituto Nacional de Antropología e Historia (INAH) durante la práctica de campo efectuada en noviembre del 2009 en la zona arqueológica de Alta Vista, Zacatecas. Uno de los objetivos de esta temporada de trabajo fue el tratamiento de las colecciones de hueso, concha, turquesa y pirita del museo de sitio. Aquí nos enfocaremos en reflexionar sobre los valores de los artefactos del museo, con énfasis en la metodología seguida en el trabajo, los tratamientos efectuados y los resultados obtenidos.

La intervención en la colección tuvo una duración de dos semanas. Aunque algunas acciones del proyecto se realizaron en la sala de exposición, gran parte se desarrollaron en un laboratorio instalado provisionalmente dentro del museo de sitio. Se trabajó un total de 91 objetos, 89 de los cuales se encontraban expuestos. Así, la primera fase de intervenciones, que principió con la selección y el desmontaje, correspondió al manejo de la colección.
\end{abstract}

\section{El manejo de la colección}

La selección de las piezas fue responsabilidad de las profesoras titulares del STORARQ a partir del catálogo fotográfico y la observación in situ de los objetos. Se eligieron aquellos que presentaban inestabilidad material y alteraciones estéticas.

Como los objetos forman parte de la exhibición permanente del museo de sitio, fue necesario diseñar e instrumentar una metodología básica que hiciera posible controlar su ubicación en el arreglo museográfico, durante su intervención y su re-montaje en vitrinas después del tratamiento.

Cabe señalar que tanto los cuerpos de seguridad del Centro INAH-Zacatecas como los directivos del museo y del Proyecto Arqueológico Alta Vista manifestaron satisfacción por el control de la colección (Figura 1). 


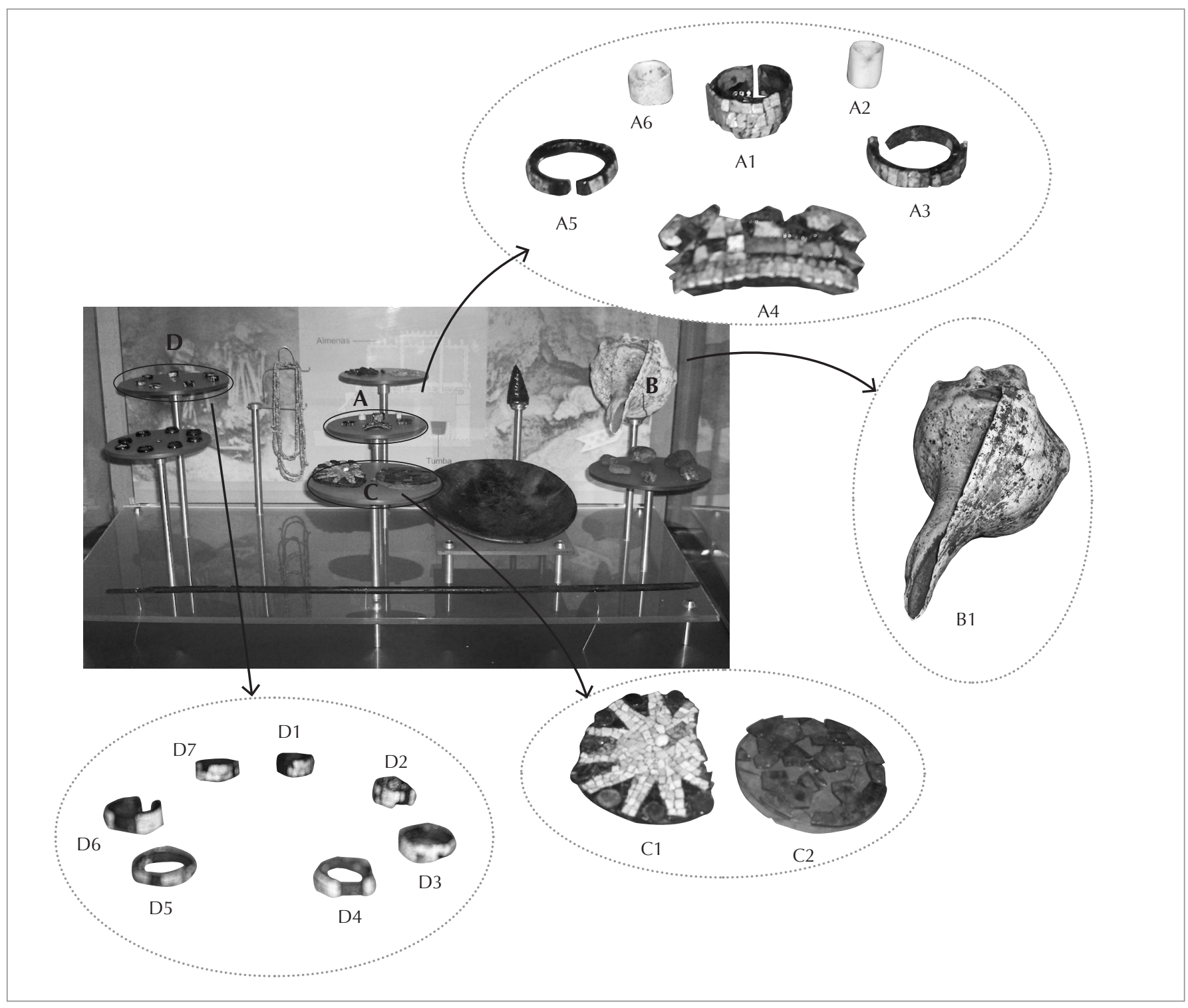

FIGURA 1. Detalle de distribución de las piezas dentro de las vitrinas del museo de sitio con las claves asignadas para el control de materiales durante la práctica de campo (Cortesía: STORARQ, ENCRYM-INAH, 2009).

\section{Documentación y valoración}

Documentar y elaborar una valoración del bien cultural que se ha de conservar es esencial, ya que ello permite no sólo reconocer por qué el objeto es importante, sino también guiar la toma de decisiones para que las intervenciones se encaminen tanto a solucionar problemas técnicos como a preservar o recuperar los valores que le dan significado y relevancia. Aunque existen muchos sistemas que incorporan la valoración en las metodologías de conservación, casi todas se refieren a sitios o monumentos.
Por ello, en esta práctica se decidió aplicar una metodología de conservación fundada en la documentación y valoración tanto en relación con los objetos como con la colección.

La documentación inició con un registro gráfico detallado de las piezas con el fin de caracterizarlas. Para esto se consultó, además de informes y estudios, a especialistas, quienes proporcionaron datos esenciales para realizar la posterior valoración. La información se sistematizó con fichas clínicas, las cuales fueron de utilidad para describir el estado de conservación de los artefactos y plantear los procesos de conservación a seguir en ellos.

En fases subsecuentes, este sistema de registro permitió consignar las intervenciones realizadas e incorporar imágenes fotográficas de antes, durante y después de proceso.

Sin duda alguna, la valoración exigió un gran esfuerzo analítico de información documental y artefactual. La discusión interdisciplinaria con los arqueólogos del sitio fue fundamental para complementar datos y conciliar visiones disímbolas. Como resultado de ello, se llegó a las siguientes conclusiones: 
La colección arqueológica del Museo de Sitio de Alta Vista, Zacatecas, no sólo presenta formas materiales y tecnológicas propias, representativas y características de la cultura Chalchihuites; de hecho, estos artefactos constituyen la materialización de una cultura de gran importancia en el complejo mesoamericano (Medina-González 2009). Efectivamente, al ser frontera entre Mesoamérica y Aridamérica, la región de Chalchihuites y el sitio de Alta Vista fungían como puntos de comercio tanto de recursos locales (piedra verde, madera, cáscara de nuez y pirita) abundantes en esta zona semidesértica, como de materiales de exportación (conchas de zonas costeras y turquesa de California, Nuevo Mexico o Guatemala). Estos materiales sirvieron para confeccionar los objetos que hoy conforman la colección del museo de sitio y son muestra de la capacidad de las redes de intercambio prehispánicas para alcanzar regiones lejanas de Mesoamérica. Particularmente, la colección de turquesas y de anillos de cáscara de nuez representan, por su abundancia y belleza, colecciones únicas en el acervo prehispánico mexicano.

Estos artefactos hacen patente que los integrantes de la cultura Chalchihuites poseían conocimientos complejos y aptitudes refinadas para elaborar bienes culturales de enorme complejidad tecnológica y artística. Ello es observable en objetos de gran calidad estética, como los mosaicos de turquesa, que representan formas realistas y abstractas, así como en objetos simples, pero de complicada fabricación, tales como los anillos de cáscara de nuez.

Gran parte de la colección se compone de materiales de lujo y prestigio, por ello reflejan el gusto y las preferencias estéticas de la élite de una cultura que llegó a su apogeo en el periodo Clásico mesoamericano.

Como lo reportan los informes del arqueólogo Charles Kelley (1971,
1974, 1976), un gran número de los artefactos en cuestión proceden de contextos rituales, por lo que reflejan las creencias de sus productores sobre la vida y la muerte. Asimismo, su incorporación en complejos votivos son manifestaciones materiales del simbolismo y de la cosmovisión de un pueblo.

Los artefactos forman parte de la historia arqueológica de Altavista, ya que fueron excavados y estudiados en los años setenta del siglo pasado por el arqueólogo Charles Kelley, y en los noventa por los arqueólogos Baudelina García Uranga y Humberto Medina González.

De lo anterior puede concluirse que la colección de hueso, concha, turquesa y materiales orgánicos del Museo de Sitio de Alta Vista es de gran relevancia en el acervo arqueológico mesoamericano, por lo que requiere una aproximación que no sólo garantice su conservación material, sino que coadyuve a la preservación y difusión de sus valores.

\section{Diagnóstico, propuesta e intervención}

Una vez concluida la valoración, se realizó un diagnóstico del estado físico de los artefactos. Un análisis conjunto de estas dos variables determinó la propuesta de conservación, en la que se incluyeron los materiales y las técnicas que se emplearían durante las intervenciones. A continuación se describen los anteriores rubros ordenados por tipo de materiales. Asimismo, se relatan las acciones llevadas a cabo y las observaciones recabadas al efectuar los tratamientos.

\section{Hueso}

La colección de hueso estuvo compuesta por 16 elementos, todos ellos fragmentos de osamentas humanas, algunos con señales de modificación cultural y otros restaurados anterior- mente mediante la unión de fragmentos, probablemente con polímeros sintéticos. Las grandes constantes de alteración fueron la disgregación y la inestabilidad estructural, por lo que se propuso realizar procesos que restablecieran su estabilidad. Este tratamiento se realizó con Reconos ${ }^{\circledR}$ 110 , una sustancia remineralizadora a base de fluoruro de sodio que ha tenido resultados satisfactorios en problemáticas análogas. También se empleó Reconos ${ }^{\circledR} 220$, un consolidante a base de quitina que ayuda a regenerar la parte orgánica del material óseo. Se seleccionaron estas sustancias porque, a diferencia de los polímeros sintéticos, no bloquean los poros del material ni alteran su aspecto. La aplicación se llevó a cabo con pincel tanto sobre la superficie interna como sobre la externa de los fragmentos óseos.

Como resultado de las observaciones se reconoció un inconveniente del tratamiento: la aplicación de Reconos $^{\circledast} 220$ causó el reblandecimiento en un par de elementos, los cuales, al secado, presentaron fisuras superficiales. Dichas alteraciones se resanaron con pasta de hueso pulverizado y Mowital ${ }^{\circledR} \mathrm{B} 60 \mathrm{H}$ al $15 \%$ en acetona, una mezcla suave y reversible (Figura 2).

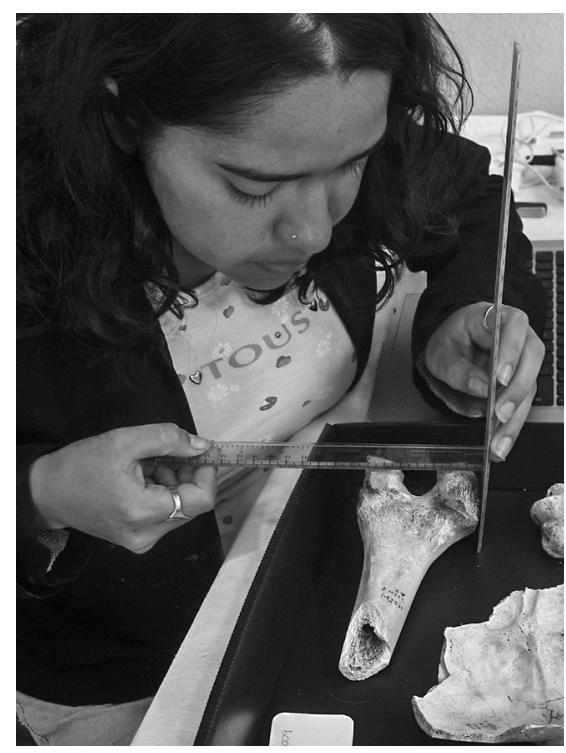

FIGURA 2. Proceso de registro de material óseo de la colección del Museo de Sitio de Alta Vista, Zacatecas, durante la práctica de campo. (Cortesía: STORARQ, ENCRYM-INAH, 2009). 


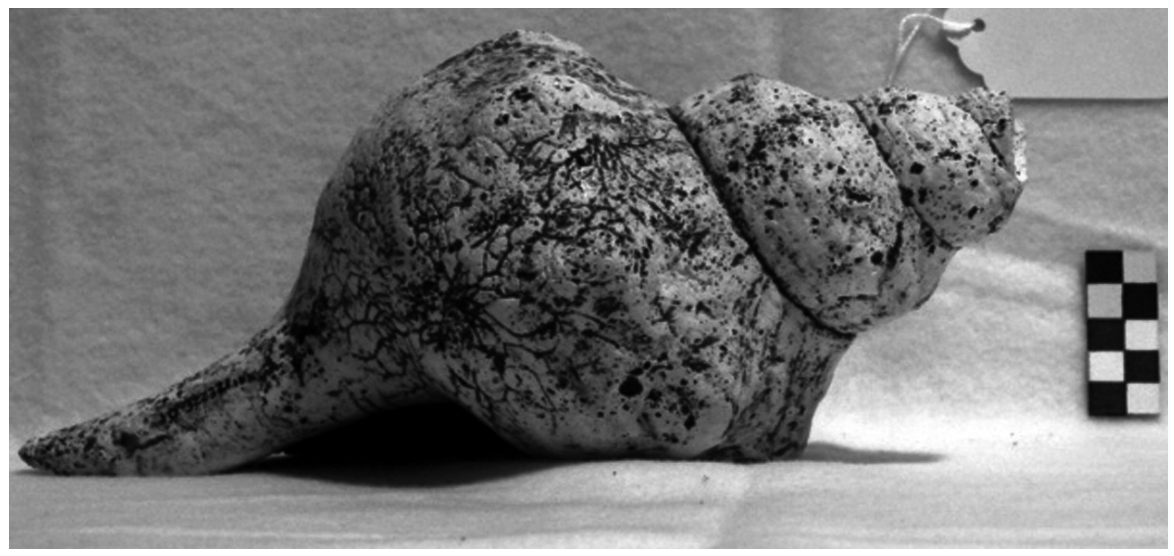

FIGURA 3. Imagen que muestra un caracol después de la aplicación de Reconos ${ }^{\circledR} 110$ y 220. (Cortesía: STORARQ,ENCRYM-INAH, 2009).

Concha

La colección de elementos de concha fue la más abundante, ya que se trabajaron 57 artefactos, algunos con evidencias de modificación cultural.

La problemática de conservación de la colección de material conquiológico era similar a la de los restos óseos, ya que presentaban disgregación e inestabilidad estructural. Aunado a lo anterior, los números de inventario habían sido colocados en las caras externas de los objetos, con lo que se invadía gran parte de su superficie y se impedía su correcta apreciación. Por lo anterior, se propuso reforzar la estabilidad material $y$, en los casos en que fuese necesario, retirar los números de inventario para colocarlos nuevamente con las dimensiones y en los lugares adecuados.

Por las cualidades anteriormente descritas, se utilizaron Reconos ${ }^{\circledR}$ 110 y 220 para la consolidación de los materiales conquilógicos. Los números de inventario se eliminaron utilizando agua-alcohol y acetona con hisopo. Para colocarlos nuevamente, primero se aplicó con pincel una capa de Mowital ${ }^{\oplus} \mathrm{B} 60 \mathrm{H}$ al 3\% en acetona, como aislante, en una pequeña zona, sobre la cual se escribieron dichos números con plumón indeleble, y se cubrieron con otra capa del polímero.

En todos los casos, los procesos llevados a cabo fueron satisfactorios, ya que se mejoró la estabilidad material y la lectura de los artefactos (Figura 3).

\section{Turquesa}

La colección de artefactos de turquesa constó de dieciocho elementos que se agruparon en tres conjuntos:

Anillos de cáscara de nuez con mosaico de turquesas.

- Mosaicos de turquesas con soporte de madera.

- Mosaicos de turquesa sin soporte.

Anillos de cáscara de nuez con mosaico de turquesas

Se restauraron 11 artefactos, todos con un soporte de cáscara de nuez, sobre el cual fue adherido, posiblemente mediante una resina natural, un mosaico de teselas de turquesa. Los elementos de esta colección habían sido intervenidos anteriormente por inmersión en algún polímero sintético.

Un aspecto digno de mencionar es que todos los anillos presentaban una abertura transversal que inicialmente se consideró como un deterioro. Sin embargo, al compararlos con la colección de anillos de cáscara de nuez sin mosaicos que alberga el propio museo de sitio, se determinó que esa abertura es un rasgo de manufactura, por lo que se decidió conservarlo, en vez de proceder a su intervención. Esto es prueba de que una evaluación correcta de las características físicas de un objeto es imprescindible para distinguir sus cualidades valorativas frente a sus deterioros.

Los anillos presentaban una compleja problemática de deterioro. Su soporte se encontraba frágil y friable, por lo que era necesario estabilizarlo y reforzarlo. Algunos de los artefactos también mostraban grietas $y$ fisuras que debilitaban su estructura. El mosaico de turquesa dejaba ver desfases en la posición de las teselas. Además, el material utilizado en la intervención anterior cubría totalmente el elemento, presentaba amarillamiento y aglutinaba restos de sedimento en su superficie, lo que afectaba la apreciación de las piezas, su diseño, así como el brillo y el color de la turquesa. Como resultado de esta afectación, los mosaicos parecían estar constituidos por piedras verdes de acabado mate.

Debido a la naturaleza del consolidante anteriormente aplicado a estos anillos, se decidió utilizar polímeros sintéticos compatibles, tanto para consolidar el soporte como para adherir las teselas una vez que se corrigieran los desfases de los mosaicos. Así, la consolidación del soporte se realizó aplicando Paraloid $^{\circledR}$ B72 al $5 \%$ en acetona con pincel. Los soportes con fisuras y grietas se reforzaron colocando de manera transversal fibras de non-woven utilizando el mismo consolidante. Las teselas que conformaban los mosaicos de turquesa se limpiaron aplicando acetona con hisopo, mientras que los restos de resina y sedimento se eliminaron con bisturí. Los desfases de las teselas se corrigieron, desmontando aquellas que se encontraban fuera de su lugar, por medio de un velado. Ello permitió un manejo seguro de las teselas para su posterior montaje en la posición correcta, aplicando Mowital ${ }^{\circledR} \mathrm{B} 60 \mathrm{H}$ al $15 \%$ en acetona.

Cabe señalar que las intervenciones fueron determinantes para optimizar la estabilidad y la lectura de los artefactos. Para evitar que ésta se interrumpiera, los refuerzos de 
non-woven se reintegraron con pinturas al barniz. Durante la corrección de desfases y el desmontado de las teselas se detectaron restos del adhesivo original de los elementos. Sin embargo, no fue posible obtener muestras, ya que los elementos estaban embebidos con el consolidante empleado en la intervención anterior. La limpieza permitió que las turquesas recuperaran su color azul y brillo característicos, lo que permite valorar realmente los artefactos como piezas de gran prestigio y lujo en la época prehispánica (Figura 4).

\section{Mosaicos con soporte de madera}

Los cuatro elementos que conforman esta colección presentan un soporte de madera, sobre el cual fueron adheridas las teselas de turquesa para formar un mosaico. Éste, a partir de una técnica compleja de manejo de teselas, representa diseños muy delicados y bellos.

Las piezas evidenciaban una serie de deterioros variables. Sus soportes presentaban grandes diferencias en su estado de conservación: dos de ellos, aunque mostraban grietas, permanecían estables, mientras que los otros dos se encontraban friables, frágiles y fisurados. Los mosaicos, como en el caso de los anillos, estaban desfasados, exhibían sedimento aglutinado en superficie, así como una capa de color amarillento que alteraba sus características ópticas.

Todos los elementos se habían consolidado en una intervención anterior con una resina sintética. Este material cubría y cambiaba la apariencia de los mosaicos, por lo que se propuso eliminar los excesos para devolver a los objetos una apariencia similar a la que tuvieron originalmente $y$, en el caso de los soportes, resanar las grietas o consolidar su material constitutivo con el fin de aumentar su estabilidad.

Como los soportes estables también contenían excedentes de material de la intervención anterior, éstos se eliminaron con hisopos embebidos en acetona. Las secciones frági-

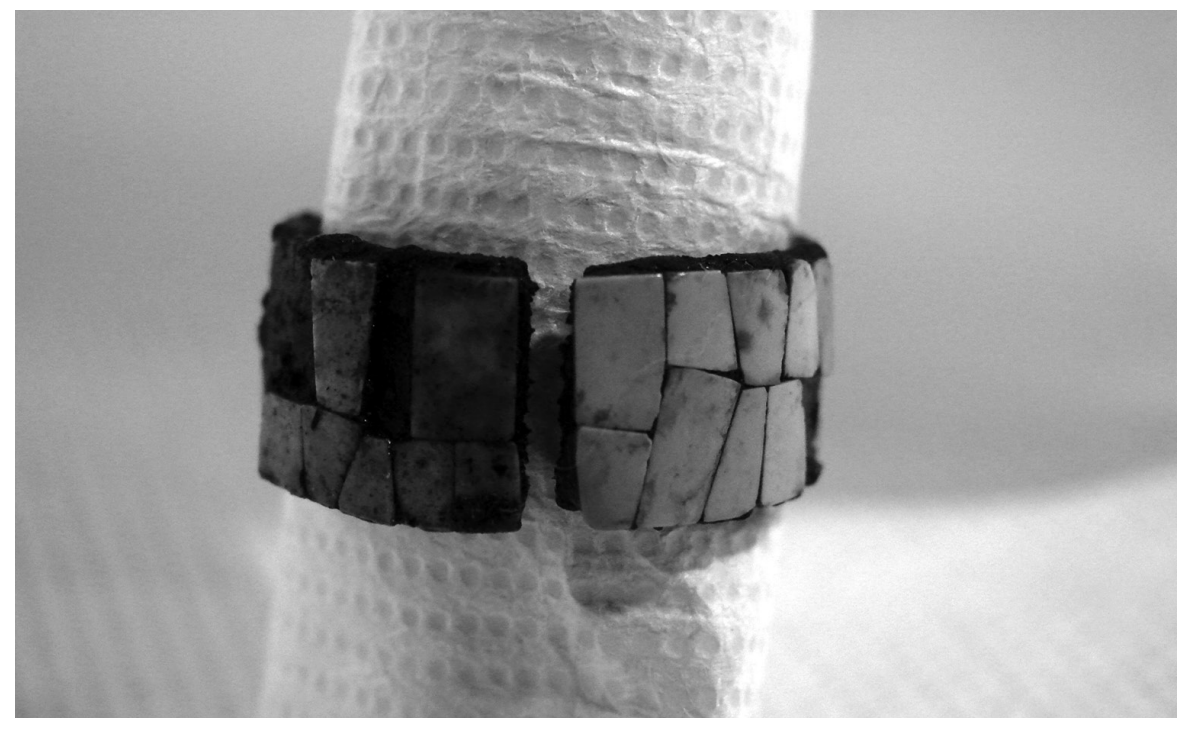

FIGURA 4. Detalle del proceso de limpieza de las teselas de turquesa de un anillo. Se observa el cambio de apariencia en el color del mosaico. (Cortesía: STORARQ, ENCRYM-INAH, 2009).

les y friables se consolidaron utilizando Paraloid ${ }^{\circledR}$ B72 al 5\% en acetona aplicado por goteo. Puesto que los objetos ya habían sido tratados con polímeros sintéticos, se eligieron materiales compatibles con la intervención anterior. Las grietas se resanaron a bajo nivel con pasta cerámica, ${ }^{1}$ homogeneizando la superficie y reforzando áreas susceptibles de rupturas. Los resanes se reintegraron con pinturas al barniz para propiciar una lectura coherente de los objetos.

Los soportes friables requirieron una intervención más compleja, por lo que para restablecer su estabilidad se elaboró una sub-base de refuerzo. Para ello, se colocó en el anverso del soporte, como interfase para asegurar la reversibilidad del proceso, una capa de non-woven adherida con Mowital ${ }^{\circledast} \mathrm{B} 60 \mathrm{H}$ al $15 \%$ en acetona. Posteriormente se aplicó una capa de resina RenPaste ${ }^{\circledast}, 2$ que se modeló en la forma necesaria. Una vez seca,

\footnotetext{
${ }^{1}$ La pasta cerámica está compuesta por Mowilith ${ }^{\circledR} 50$, caolín, blanco de España, fibra de vidrio y acetona. Se utiliza en México desde hace varias décadas para resanar cerámica arqueológica, puesto que se trata de un material maleable, ligero, inocuo y reversible.

2 Esta resina epóxica es estable y permite el modelado para dar la forma específica de los elementos.
}

esta sub-base de refuerzo se reintegró con pinturas al barniz en tono y textura similares al soporte de madera original.

Las teselas se limpiaron con hisopos embebidos en acetona, así como con bisturí, para eliminar tanto la capa de polímero amarillenta que las cubría como los sedimentos adheridos. Este proceso cambió radicalmente el aspecto de los artefactos, ya que como sucedió con los anillos, las teselas recuperaron el color, el brillo y la apariencia de la turquesa. La intervención de esta colección fue más que satisfactoria; además de que aseguró la estabilidad de los objetos, se recuperó el valor estético de la compleja manufactura de los mosaicos de turquesa (Figura 5), lo cual abrió nuevas posibilidades de investigación sobre la importancia de la colección del Museo de Sitio de Alta Vista en relación con series análogas ubicadas en museos nacionales y extranjeros.

\section{Mosaicos sin soporte}

Estos dos mosaicos perdieron su soporte, ya durante el enterramiento, su extracción o previa intervención. Como una solución a su exhibición museográfica, los mosaicos se adhirieron con resinas sintéticas brillantes 


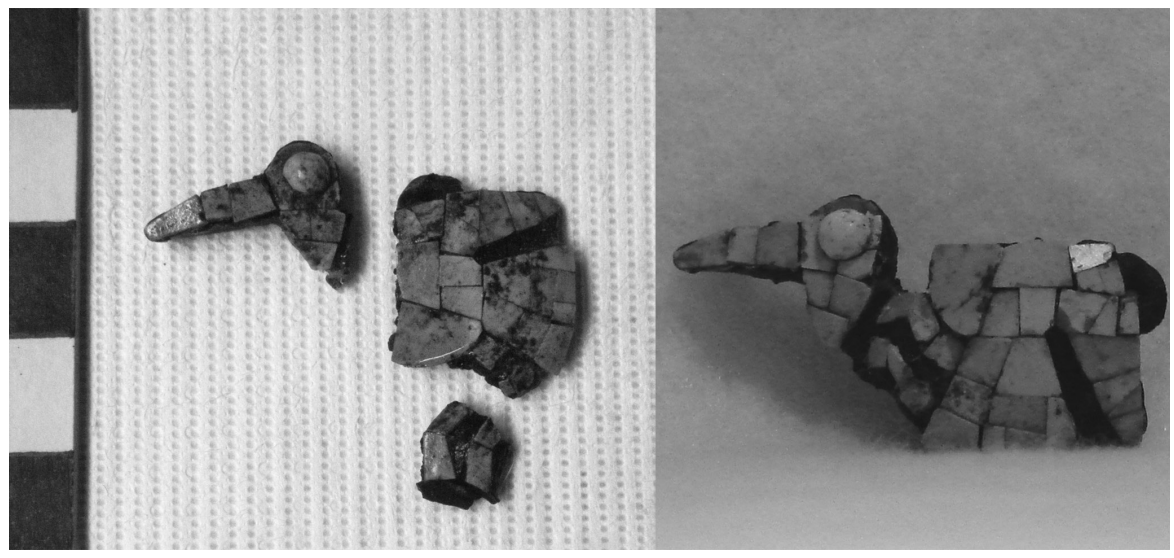

FIGURA 5. Mosaico de turquesa antes y después de intervención; el soporte de éste fue realizado con RenPaste ${ }^{\circledast}$. (Cortesía: STORARQ, ENCRYM-INAH, 2009).

sobre papeles de diversa naturaleza, forma y color. Por su flexibilidad, fragilidad y aspecto, dicho sistema de soporte presentaba varios inconvenientes; de ahí que se haya propuesto cambiarlo por otro material que proporcionara mayor estabilidad al mosaico y que fuera compatible con la museografía del lugar. Un requerimiento de la intervención fue la retratabilidad; es decir, que, ante mayor información en un futuro, los elementos puedan reintervenirse sin provocar daños en su forma y acomodo.

Con el fin de conservar la posición de las teselas, se realizó una calca de los mosaicos en papel albanene. Posteriormente se hizo un velado con Mowilith ${ }^{\circledR}$ DHLR y papel non-woven. Una vez seco el velado, se eliminó el soporte del papel y se procedió a la limpieza de las teselas por el reverso, utilizando bisturí y acetona aplicada con hisopo. Cuando se eliminó la resina usada como adhesivo, se llevó a cabo el montaje en un nuevo soporte, conformado por una placa de acrílico; se optó por ésta por ser de material inocuo, resistente y compatible con la museografía del lugar. Las teselas se adhirieron al nuevo soporte utilizando Mowital ${ }^{\oplus}$ $\mathrm{B} 60 \mathrm{H}$ al $15 \%$ en acetona. Se eliminó el velado y se limpiaron las teselas por el anverso utilizando agua tibia y agua-alcohol, mediante papetas e hisopo.

La intervención realizada en estos elementos permitió integrar las so- luciones de conservación a los requerimientos de la museografía existente.

Pirita

El mosaico de pirita del museo de sitio de Alta Vista es único en la colección. Se trata de un elemento circular cuyas teselas se desprendieron de su soporte de piedra arenisca fragmentado, posiblemente durante su extracción del depósito arqueológico. En una intervención anterior, las teselas fueron adheridas con resina sintética a una hoja de acetato; un soporte secundario que, sin embargo, no cumplía satisfactoriamente con las funciones de refuerzo, al no ser capaz de sostener el peso de las láminas de pirita. Aunado a lo anterior, el mosaico presentaba pérdida de elementos y el adhesivo se había tornado amarillento, afectando la apariencia de un objeto de gran valor arqueológico.

Con base en esta evaluación se propuso cambiar el soporte para mejorar la estabilidad del artefacto. Asimismo, se planteó la necesidad de facilitar una mejor apreciación de sus valores estéticos.

Primeramente, las teselas de pirita se calcaron en papel albanene para conservar su acomodo. Luego, se procedió a velarlas y desprenderlas del acetato con materiales similares a los empleados en los mosaicos de turquesa. Se retiró el adhesivo del reverso utilizando acetona aplicada con hisopo. El proceso de limpieza se realizó en un ambiente cálido generado con una secadora de cabello con el fin de evitar un cambio de aspecto de la pirita. ${ }^{3}$ Aunque se decidió mantener la idea de un soporte secundario con el objetivo de garantizar la reversibilidad en el proceso, el acetato se cambió por una placa de acrílico, la cual ofrecía la rigidez y la transparencia deseadas.

Durante la intervención, se observó que las teselas se encontraban en un orden que no correspondía con la configuración original del mosaico. La forma de las láminas y su corte permitieron su reacomodo en el nuevo soporte secundario mediante el uso de adhesivo Mowital ${ }^{\circledR} \mathrm{B} 60 \mathrm{H}$ al $15 \%$ en acetona, un material que posibilita la re-tratabilidad en el futuro, en caso de llegar a contar con evidencias adicionales sobre su aspecto original.

\section{Conclusiones}

El trabajo aquí presentado permite concluir que tanto el manejo de la colección como los tratamientos realizados fueron exitosos, ya que cumplieron el objetivo principal de la práctica: conservar y restaurar un acervo de artefactos arqueológicos ubicados en un contexto museográfico de sitio. Los resultados del trabajo fueron satisfactorios, ya que las colecciones no sólo fueron estabilizadas, sino que ahora hacen legibles sus valores más relevantes.

Una de las conclusiones más significativas fue que el buen término de un trabajo de conservación de campo con una colección numerosa de piezas en exhibición requiere necesariamente planificación y seguimiento. La primera se logra a partir de la instrumentación de metodologías claras que sistematizan y controlan, por un lado, el manejo de las colecciones, y, por el otro, su propia intervención.

\footnotetext{
${ }^{3}$ En ambientes fríos, la evaporación del solvente genera en la pirita una apariencia blanquecina.
} 
La valoración de los artefactos arqueológicos fue esencial, ya que permitió acercarse al significado y relevancia de los objetos y la colección, lo que condujo a una intervención informada, respetuosa, coherente con sus necesidades y que favoreció su comprensión y lectura.

La observación de los anillos de mosaico de turquesa permitió que se definieran características propias de la técnica de manufactura que en un inicio se habían confundido con efectos del deterioro. Asimismo, se observó la presencia de resinas naturales que originalmente sirvieron para adherir los mosaicos al soporte. Sin embargo, debido a las intervenciones anteriores, será muy difícil caracterizar la naturaleza de este material adhesivo prehispánico. Con los procesos de limpieza se hizo más evidente el color de las teselas, lo que tendió a confirmar que se trata de turquesa y no de malaquita, como está registrado en el catálogo del museo. En un futuro será necesario realizar análisis petrográficos para confirmar que este tipo de mineral está efectivamente involucrado en la manufactura de las teselas.

Un beneficio adicional de la práctica fueron las observaciones sobre el uso de materiales relativamente nuevos en el campo de la conservación arqueológica, como el Reconos ${ }^{\circledR}$ y la resina RenPaste ${ }^{\circledast}$. Aunque los resultados obtenidos con el Reconos $220^{\circledR}$ fueron favorables en la mayoría de los casos, en tanto que devolvieron al hueso sus características de dureza y resistencia, es recomendable profundizar sobre su aplicación para evitar alteraciones colaterales.
La realización de soportes para elementos de pequeño formato con la resina RenPaste ${ }^{\circledast}$ fue una experiencia interesante, ya que además de que brinda un soporte estable al artefacto, su preparación es simple y permite acciones de modelado, aplicación de textura y reintegración cromática. Ello ofrece una garantía de resultados satisfactorios tanto materialmente como en relación con su integración estética.

No hay que olvidar que la presente práctica fue parte de un proceso formativo profesional. Ello significó que la propia dinámica de trabajo capacitó no sólo en lo que se refiere a procesos e intervenciones, sino también acerca de metodologías de conservación, estrategias de planificación y formas de trabajo. Así, la experiencia, si bien consistió en trabajar materiales arqueológicos de gran importancia con intervenciones anteriores poco afortunadas, fue significativa en tanto que dio a conocer a una realidad con tiempos, necesidades y circunstancias propias del quehacer profesional, en la que los beneficios de la colaboración interdisciplinaria fueron indiscutibles. Por ello, la oportunidad de participar en una dinámica real de colaboración entre especialistas de diferentes profesiones representó una lección contundente.

Para finalizar, se han abierto preguntas de investigación en las áreas de arqueología, museografía y de conservación arqueológica. Así, el valor de la práctica escolar se transforma en su capacidad de formar profesionales capaces de investigar y preservar el rico legado arqueológico de nuestro país.

\section{Referencias}

Kelley, Charles

1971 "Informe de trabajo de la temporada de excavación arqueológica", documento inédito, México, Archivo Arqueológico del Centro INAH Zacatecas. 1974 "Informe de trabajo de la temporada de excavación arqueológica", documento inédito, México, Archivo Arqueológico del Centro INAH Zacatecas.

1976 "Informe de trabajo de la temporada de excavación arqueológica", documento inédito, México: Archivo Arqueológico del Centro INAH Zacatecas.

Medina-González, Isabel

2009 "Proyecto para la Conservación Integrada del 'Relieve Picacho Pelón', Zona Arqueológica de Alta Vista, Chalchihuites", Zacatecas, documento inédito. México, Archivo CNCPC-INAH.

\section{Agradecimientos}

Agradecemos a la maestra Isabel MedinaGonzález por incorporar esta práctica de campo dentro del "Proyecto para la Conservación Integrada del Relieve 'Picacho Pelón'", y a la arqueóloga Baudelina García Uranga (coordinadora del Proyecto Arqueológico Alta Vista), por confiarnos el trabajo de tan importante e interesante colección. Debemos gratitud a la arqueóloga Patricia Monreal (directora del Museo de Sitio de Alta Vista), al C. Antonio de Dios Sánchez (jefe de seguridad del Centro INAH Zacatecas), al arqueólogo Humberto Medina González y a los custodios del sitio, quienes nos brindaron información, apoyo y todas las facilidades para el desarrollo de nuestro trabajo. Finalmente, nuestro reconocimiento a la maestra Carolusa González Tirado por su invaluable ayuda en la elaboración de este artículo. 


\section{Resumen}

En noviembre del 2009, el Seminario-Taller de Rescate Arqueológico de la ENCRym realizó en el Museo de Sitio de la Zona Arqueológica de Alta Vista, Zacatecas, una práctica de campo, cuyo objetivo fue intervenir una colección de 91 artefactos arqueológicos elaborados en concha, hueso, turquesa y pirita que se encuentran en exhibición. Este artículo versa sobre las actividades realizadas y los resultados obtenidos en dicha práctica. Se analiza el proceso de conservación, que incluye la valoración de los artefactos, su diagnóstico, la propuesta de trabajo y las intervenciones realizadas. Gracias a esta perspectiva para la toma de decisiones, la conservación no sólo proporcionó resultados favorables, sino que además se realizaron observaciones relativas a la técnica de manufactura de los objetos, las limitaciones de los tratamientos realizados y las posibilidades de integración museográfica. Así, esta práctica constituyó un ejemplo de la importancia de la interdisciplina en la conservación arqueológica y de la aportación que los restauradores pueden hacer al ámbito transprofesional.

Palabras clave

Alta Vista, Reconos ${ }^{\circledast}$, colecciones, materiales arqueológicos, montaje.

\section{Abstract}

The Archaeological Conservation Seminar ENCRYM-INAH held a field trip to the archaeological site of Altavista, Zacatecas during November 2009. Its objective was to conserve a collection of 91 archaeological artifacts made from shell, bone, turquoise and pyrite. The decisions on materials and methods of treatment as well as the achievements are discussed. The restoration procedures were carefully chosen after analyzing the objects and their state of material conservation. This practical experience in conservation reported not only satisfactory results but also useful data regarding the technology of the artifacts, the limitations of certain conservation procedures, and possibilities for museographic integration. This field trip is an example of interdisciplinary work in archaeological conservation and highlights the contributions to the professional area the conservators can generate.

\section{Keywords}

Alta Vista, Reconos ${ }^{\circledR}$, Collections, Archaeological materials, Display. 